NOTICE: this is the author's version of a work that was accepted for publication in Water Research. Changes resulting from the publishing process, such as peer review, editing, corrections, structural formatting, and other quality control mechanisms may not be reflected in this document. Changes may have been made to this work since it was submitted for publication. A definitive version was subsequently published in Water Research, Vol. 50 (2014).

DOI: 10.1016/j.watres.2013.10.056 


\section{Assessment of wastewater and recycled water quality: A comparison of lines \\ 2 of evidence from in vitro, in vivo and chemical analysis}

3 Frederic D.L. Leusch ${ }^{a}$, Stuart J. Khan ${ }^{b}$, M. Monique Gagnon ${ }^{c}$, Pam Quayle $^{a}$, Trang Trinh ${ }^{b}$, Heather

4 Coleman $^{b}$, Christopher Rawson $^{c}$, Heather F. Chapman ${ }^{a}$, Palenque Blair $^{d}$, Helen Nice and Tarren $^{e}$

5 Reitsema $a^{e, f}$

6 a Smart Water Research Centre, Griffith University Gold Coast Campus, Southport, QId 4222, Australia

$7 \quad$ bater Research Centre, University of New South Wales, Sydney, NSW 2052, Australia

$8 \quad{ }^{c}$ Curtin University, Perth, WA 6102, Australia

$9 \quad$ Water Corporation, Perth, WA 6007, Australia

10 eWater Science Branch, Department of Water, Perth, WA 6169, Australia

$11{ }^{\mathrm{f}}$ National Offshore Petroleum Safety and Environmental Management Authority, Perth, WA,

12 Australia

*Corresponding author: f.leusch@griffith.edu.au; tel (61)7 55527832

\section{Abstract}

Water quality was characterised at an advanced water reclamation plant and three conventional wastewater treatment plants in Southwest Western Australia using a battery of five in vitro bioassays. The bioassay battery included endpoints for bacterial toxicity (Microtox), genotoxicity (umuC), photosynthesis inhibition (Max-I-PAM) and endocrine effects (E-SCREEN and AR-CALUX), chosen to provide an appropriately wide coverage of biological effects in the context of managed 
aquifer recharge and environmental discharge of treated wastewater. Chemical analysis of hormones and pesticides using LCMSMS was performed in parallel to correlate standard analytical methods with the in vitro assessment. For two plants with surface water discharge into drains, further field work was carried out to examine in situ effects using mosquitofish (Gambusia holbrooki) as a bioindicator species for possible endocrine effects. The results show considerable cytotoxicity, phytotoxicity and estrogenicity in raw sewage, which was significantly reduced by conventional wastewater treatment. No biological response was detected to RO water, suggesting that reverse osmosis is a significant barrier to biologically active compounds. Chemical analysis and in situ monitoring revealed trends consistent with the in vitro results: chemical analysis confirms the removal trends observed by the bioanalytical tools, and in situ sampling did not reveal any evidence of endocrine disruption specifically due to discharge of treated wastewater (although other sources may be present). This study illustrates the utility of combining multiple lines of evidence, including chemical analysis, an in vitro toolbox, and in situ monitoring in the assessment of water quality.

Keywords: chemical analysis; in vitro bioassay; mosquitofish; wastewater; water quality; water recycling

- In vitro bioassays were combined with chemical analysis and in situ sampling.

- Four Western Australian wastewater treatment plants were monitored.

- Slight estrogenic endocrine disruption was detected in receiving environments.

- The three lines of investigation agreed and provided a more complete assessment.

\section{Introduction}


44 There are several methods that can be used to inform environmental risk assessment. Chemical analysis is widely used and well-grounded in regulatory frameworks, but is limited by a priori selection of analytes and does not allow assessment of mixture toxicity effects. Assessment of whole animals in the receiving environment (in situ analysis) is commonly used to detect toxicants and determine mixture toxicity effects of wastewater, but raises animal ethics issues and is often limited in predictive ability due to complex interactions with environmental factors (such as seasonal variations). In vitro bioassays go some way to addressing the limitations of both chemical and in vivo analysis and share a mixture of their advantages (e.g., assessment of mixture toxicity, focus on chemical-mediated effects without interference from environmental factors, no ethical issues) and some of their disadvantages (e.g., inability to positively identify causative compounds and accurately predict whole organism effects). Bioanalytical tools also have some unique advantages, including lower detection limits and high throughput screening, and some unique disadvantages such as a lack of regulatory acceptance (Escher and Leusch 2012, Power and Boumphrey 2004). A combination of these different methods would provide valuable additional information to complement the current traditional approach.

Climate change has reduced rainfall and significantly diminished water availability over the last 30 years in the South West of Australia and further decline is expected over the next 50 years (CSIRO \& BOM 2007). At the same time Perth (Western Australia, WA) has an increasing population and competing demands for water. Consequently local authorities are trialling Groundwater Replenishment to supplement aquifers with water reclaimed from urban wastewater at an Advanced Water Reclamation Plant (AWRP). There are also a number of rural wastewater treatment plants (WWTPs) that currently dispose of treated wastewater by discharge to the freshwater environment. The potential for environmental impacts as a result of the ecotoxicity of this effluent is not well understood. This study was undertaken as part of a comprehensive research agenda to 
better understand the environmental risks associated with managed aquifer recharge (Water Corporation 2013).

We investigated the suitability of using three complementary analysis (chemical analysis, in vitro bioanalysis and in situ biological monitoring) to detect biologically active compounds during wastewater treatment, with a focus on endocrine disruption. We used an "ecotoxicity toolbox" to characterise water quality through the wastewater treatment process. The toolbox includes in vitro endpoints for bacterial toxicity (Microtox), genotoxicity (umuC), photosynthesis inhibition (Max-IPAM) and endocrine effects (E-SCREEN and AR-CALUX). The bioassays were chosen to provide an appropriately wide coverage of biological effects relevant to managed aquifer recharge and environmental discharge of treated wastewater. Chemical analysis using LCMSMS of hormones and pesticides was performed in parallel to correlate standard analytical methods with the in vitro assessment. An AWRP in Perth and three WWTPs in neighbouring rural and urban communities were monitored to represent a range of treatment, water quality and end-uses. Samples were taken at various steps in the treatment train in order to characterise water quality through the treatment process. For those plants with surface water discharge into drains (WWTPs 1 and 2), further field work was carried out to examine in situ effects using mosquitofish (Gambusia holbrooki) as a bioindicator species for possible endocrine effects.

The aims of this study were: 1 ) to analyse water reclaimed by advanced water treatment (including reverse osmosis) intended for managed aquifer recharge with a combination of chemical analysis and in vitro bioassays; 2 ) to analyse raw, partly and fully treated wastewater at two municipal and two rural WWTPs using chemical and in vitro methods to determine the quality of representative wastewater in WA; 3 ) to examine biomarkers of exposure to endocrine disrupting compounds in mosquitofish captured in drains upstream and downstream of two of those WWTPs and analyse water quality at those same sites with the in vitro bioassay battery; and 4) to compare the results of 

the three methods (chemical, in vitro and in situ) and further our understanding of their value in risk assessment.

\section{Materials and methods}

95

\subsection{Site description}

Four WWTPs were sampled in this study (Fig 1). The AWRP is a major urban WWTP with a small pilot plant AWRP for trial of groundwater replenishment that includes reverse osmosis (RO) treatment; WWTP 1 and 2 are small rural plants providing secondary treatment of wastewater from country towns with discharge into drains; and WWTP3 is a secondary treatment plant with infiltration to a superficial aquifer with downstream abstraction for irrigation use. The WWTPs were selected to provide a range of treatment technologies and type of end-use/receiving environment typical of Southwest WA.

\section{[INSERT FIG 1 ABOUT HERE]}

Several stages of the treatment trains were sampled (Fig. 1), including raw, partially and fully treated wastewater, and RO permeate at the AWRP. The AWRP was sampled in March, June, September and December 2008. The three WWTPs were sampled in June, September and December 2008 and March 2009. Discharge drains upstream and downstream of WWTP 1 and 2 and a reference site adjacent to the Serpentine National Park were also sampled in December 2008.

\subsection{Water sampling and extraction}

Quadruplicate samples were taken quarterly over a year at each location: two samples for bioassays, and two samples spiked with deuterated hormone surrogates for chemical analysis.

Water samples ( $1 \mathrm{~L}$ for raw sewage, $2 \mathrm{~L}$ for all other samples) were collected in methanol-rinsed amber glass bottles by flow-averaged autosampler (AWRP) or by grab samples (all others) and 
immediately processed. Samples were filtered (AP20 glass fibre filters; Millipore) and extracted by solid-phase extraction using 20 cc Oasis HLB cartridges using the method described in Leusch et al. (2006). In brief, cartridges were pre-conditioned with $10 \mathrm{~mL}$ methanol and $10 \mathrm{~mL}$ ultrapure water. After passing the entire water sample, the cartridges were air-dried for $2 \mathrm{~h}$. They were eluted with $2 \times 10 \mathrm{~mL}$ methanol, evaporated to near dryness under a gentle stream of nitrogen, and reconstituted in $500 \mu \mathrm{L}$ methanol. The eluates were analysed by in vitro bioassays and chemical methods. For the first two sampling events (March and June 2008), $10 \mathrm{~mL}$ acetone:hexane (1:1) was also used in addition as first conditioning solvent and last elution solvent. In September 2008, side-by-side experiments with wastewater samples showed no significant difference in chemical and bioanalytical results when using acetone:hexane and methanol vs. methanol only as conditioning and elution solvent (data not shown), and methanol only was used for the 3 remaining sampling events.

\subsection{Bioanalytical toolbox}

The Microtox assay measures inhibition of bioluminescence of the naturally-bioluminescent marine bacteria Vibrio fischeri. This inhibition is caused by acute cellular toxicity or interference with energy generation pathways, and is responsive to a wide range of toxic chemicals. The assay is used here as representative of non-specific toxicity to bacteria. The assay was adapted from ISO (2007) and performed as described in Escher et al. (2008b). The bioassay threshold (i.e., value above which adverse effects may be expected in the receiving environment) was set to 1 TU (see SI 1.1).

The umuC assay measures induction of the SOS response in genetically modified Salmonella typhymurium. The SOS response is induced in response to single-stranded DNA damage. This bioassay is used here as representative of genotoxicity to bacteria, plants and animals. The assay was adapted from ISO (2000) and performed as described in Macova et al. (2011). The bioassay threshold was set to 1 GTU (see SI 1.2). The umuC assay was run both with and without a liver 
enzyme fraction (S9), however the data trends were very similar (data not shown) and only the data without metabolic activation are presented here.

The Max-I-PAM measures changes in photosynthetic capacity of the algae Chlorella vulgaris, and is generally responsive to herbicides. The bioassay is used as representative interference with photosynthesis, a measure of phytotoxicity. The assay was adapted from Schreiber et al. (2007) and performed as described in Escher et al. (2006). The reference compound for this assay was diuron $\left(\mathrm{EC}_{50}=16.8 \pm 1.5 \mu \mathrm{g} / \mathrm{L}\right)$ and the method detection limit was $0.03 \mu \mathrm{g} / \mathrm{L}$ diuron equivalent (DEQ). The bioassay threshold was set at $0.2 \mu \mathrm{g} / \mathrm{L}$ DEQ (see SI 1.3).

The E-SCREEN assay measures proliferation of MCF7-BOS breast cancer cells (a gift of Dr Ana Soto, Tufts University), which occurs in the presence of estrogenic compounds such as estrogens and estrogen mimics. The assay is used here as representative of estrogenic endocrine disruption. The assay was adapted from (Soto et al. 1995) and performed as described in (Leusch et al. 2005). The reference compound for this assay was $17 \beta$-estradiol $\left(E_{2} ; E C_{50}=6.5 \pm 0.5 \mathrm{ng} / \mathrm{L}\right)$ and the method detection limit was $0.02 \mathrm{ng} / \mathrm{L}$ estradiol equivalent (EEQ). The bioassay threshold was set at $0.1 \mathrm{ng} / \mathrm{L}$ EEQ (see SI 1.4).

Finally the AR-CALUX assay measures induction of an androgenic reporter gene in a geneticallymodified human cell line, and is responsive to androgens and androgen mimics. The assay is used here as representative of androgenic endocrine disruption. The assay was adapted from Sonneveld et al. (2005) and performed as described in van der Linden et al. (2008). The reference compound for this assay was $5 \alpha$-dihydrotestosterone $\left(\mathrm{DHT} ; \mathrm{EC}_{50}=47.7 \pm 3.1 \mathrm{ng} / \mathrm{L}\right)$ and the method detection limit was $2.5 \mathrm{ng} / \mathrm{L}$ DHT equivalent (DHTEQ). The bioassay threshold was tentatively set at $10 \mathrm{ng} / \mathrm{L}$ DHTEQ (see SI 1.5).

\subsection{Chemical analysis}


161 A range of androgen and estrogen hormones were analysed by HPLC-MS/MS analysis as described in Le-Minh et al. (2010). The estrogenic and androgenic hormones analysed (with the limit of reporting) were: the androgens androstenedione (1 ng/L), androsterone $(50 \mathrm{ng} / \mathrm{L})$, etiocholanolone $(100 \mathrm{ng} / \mathrm{L})$, testosterone (1 ng/L), $5 \alpha$-dihydrotestosterone ( $50 \mathrm{ng} / \mathrm{L})$, testosterone propionate $(5 \mathrm{ng} / \mathrm{L})$ and $17 \beta$ $\mathrm{ng} / \mathrm{L})$, estriol ( $50 \mathrm{ng} / \mathrm{L}$ ) and $17 \alpha$-ethinylestradiol $(5 \mathrm{ng} / \mathrm{L})$.

The following pesticides were measured: flumeturon, diuron, simazine, atrazine, desethyl atrazine, desisopropyl atrazine, hexazinone, tebuthiuron, ametryn, prometryn, bromacil, terbutryn, metolachlor and imidacloprid. The reporting limit for all compounds was $0.025 \mu \mathrm{g} / \mathrm{L}$. The compounds were analysed by HPLC-MS/MS using an AB/Sciex API300 mass spectrometer (AB/Sciex Concord, Ontario, Canada) equipped with an electrospray (TurboSpray) interface coupled to a Shimadzu LC10AD HPLC system (Shimadzu Corp., Kyoto, Japan). Separation was achieved using a $5 \mu \mathrm{m} 150 \times 3$ $\mathrm{mm}$ Aquastar column (Thermo Scientific, Australia) run at 40 으, and a flow rate of $0.6 \mathrm{~mL} / \mathrm{min}$ with a linear gradient starting at 10\% B for $1 \mathrm{~min}$, ramped to $100 \%$ B in $6 \mathrm{~min}$, held for $2.5 \mathrm{~min}$ and then set to $10 \% \mathrm{~B}$ in $15 \mathrm{sec}$ and equilibrated for 4 minutes $(A=10 \%$ methanol/HPLC grade water, $B=90 \%$ methanol/HPLC grade water, both containing $5 \mathrm{mM}$ ammonium acetate). The mass spectrometer was operated in positive ion multiple reaction-monitoring mode using nitrogen as the collision gas. Positive samples were confirmed by retention time and by comparing transition intensity ratios between the sample and an appropriate concentration standard from the same run. Samples were reported as positive if the two transitions were present, retention time was within $9 \mathrm{sec}$ of the standard and the relative intensity of the confirmation transition was within $20 \%$ of the expected value. 
Mosquitofish were collected in September 2008, March and July 2009 (Spring, Summer and Winter) immediately downstream of the discharge point of WWTP 1 and 2. For each WWTP an upstream site was selected for sampling with considerations of low potential of population mixing between the two sites on the same stream. Fish were also collected in the Serpentine River at a site adjacent to Serpentine National Park (reference site).

On each sampling occasion up to 100 individuals were collected until the catch per unit effort became too low to justify further capture. Twenty adult males (identified by the presence of an elongated anal fin) and 6 females (identified by a black spot on the ventral side of the abdomen) were snap-frozen in liquid nitrogen. The remainder were transported on ice to the laboratory.

Fish were categorised as adult male, immature male, adult female and immature female. Sex and stage of maturation based on anal fin morphology was determined using the methods described by Rawson et al. (2009). Morphometric measurements including gonopodial length (GL), pre-anal length (PAL), $6^{\text {th }}$ ray length (based on Game et al. 2006), standard length and wet weight were made on mature and immature male fish.

Vitellogenin was quantified in fish taken from each site in Summer (March 2009) and Winter (July 2009). Where possible 20 male and 6 female fish from each sampling site were homogenised in 1:4 (w:v) Tris buffer ( $3 \mathrm{mM}$ Tris, $0.1 \mu \mathrm{M}$ PMSF). The homogenates were centrifuged at $8000 \times g$ for 40 minutes at $4 \stackrel{\circ}{\circ}$. Homogenates and a salmonid vitellogenin standard (Biosense Laboratories, Bergen, Norway) were diluted (1:1000) in a carbonate/bicarbonate buffer (50 mM, pH 9.6). Samples and standard were added to wells of a clear 96 -well plate and allowed to incubate for $24 \mathrm{~h}$ at 4 으. The plates were then washed with phosphate buffered saline (0.05\% Tween). A 1\% BSA blocking solution was added to each well and, following $1 \mathrm{~h}$ incubation, the monoclonal antibody BN-5 (Biosense Laboratories) was added and incubated for $1 \mathrm{~h}$ at $37 \stackrel{\circ}{\circ} \mathrm{C}$. The plates were again washed (3x) and a goat anti-rabbit HRP conjugate (Biosense Laboratories) was added for a further $1 \mathrm{~h}$ 

added to the wells for a 15 min dark incubation. The reaction was stopped with $2 \mathrm{M} \mathrm{H}_{2} \mathrm{SO}_{4}$ and the absorbance read immediately at $490 \mathrm{~nm}$.

\subsubsection{Bioanalytical data analysis}

214 Biological response in water samples was quantified by calculating their $\mathrm{EC}_{50}$ in each bioassay, expressed in units of Relative Enrichment Factor REF (calculated by dividing the sample concentration from solid phase extraction by the dilution in the assay, as described in Macova et al. (2011)).

Microtox results are expressed as Toxic Unit (TU), calculated as $1 / \mathrm{EC}_{50 \text { (REF) }}$ of the sample; umuC results are expressed as genotoxic unit (GTU), calculated as 1/EC 50 (REF). Max-I-PAM, E-SCREEN and AR-CALUX results are expressed as bio-equivalents, calculated as $\mathrm{EC}_{50}$ of the reference compound (diuron, $17 \beta$-estradiol and $5 \alpha$-dihydrotesterone, respectively) divided by $\mathrm{EC}_{50 \text { (REF) }}$ of the sample.

\subsubsection{Predicted biological response}

In vitro responses could be predicted for estrogenicity, androgenicity and photosynthesis inhibition by multiplying the concentration of selected compounds by their relative potency (RP; determined in this study) in the relevant assay. Cytotoxicity and genotoxicity can be caused by a wide variety of compounds, and it was therefore not possible to relate those biological endpoints to chemical analysis. $(R P=0.071) ;$ predicted androgenicity was calculated from androstenedione $(R P=0.057)$, 
androsterone $(\mathrm{RP}=0.006)$, testosterone $(\mathrm{RP}=0.21)$, testosterone propionate $(\mathrm{RP}=0.20)$ and $17 \beta$ trenbolone $(\mathrm{RP}=0.50)$; photosynthesis inhibition was calculated from diuron $(\mathrm{RP}=1)$.

For in situ measurements, differences in GL and PAL were analysed using single factor analysis of covariance (ANCOVA) with the length of the fish as a covariate. The assumptions of homogeneous covariate slopes and equal variances between groups were satisfied. Sex ratios were examined using a binomial test.

\section{Results and discussion}

\subsection{Bioanalytical}

In general, raw sewage caused high in vitro responses, however wastewater treatment effectively removed most of the activity and the treated wastewater samples were generally below bioassay threshold values (Fig. 2). At the AWRP, the aerobic and anaerobic digestion (secondary treatment) and reverse osmosis provided most of the removal, while the oxidation ditch at WWTP3 performed generally well (although it created short-lived genotoxicity). The raw sewage at the rural WWTPs

244 (WWTP 1 and 2) was much less toxic than at the municipal plants (AWRP and WWTP3), and the pond-based treatment systems were adequate at reducing the toxicity to levels comparable to AWRP secondary-treated wastewater and WWTP3 effluent. The site downstream of WWTP2 discharge induced slightly higher biological response in vitro compared with the upstream site, although it was usually below bioassay threshold levels. 
251 At the municipal plants (AWRP and WWTP3), raw sewage was acutely toxic to bacteria but aerobic and anaerobic digestion (at AWRP) and the oxidation ditch (at WWTP3) reduced the toxicity of the water by $89-92 \%$ and $70-91 \%$, respectively. This suggests that toxic chemicals are either mineralised to less toxic degradation products or absorbed to sludge particles and removed from the water stream. At the rural plants (WWTP 1 and 2), raw sewage was not particularly toxic to bacteria $(<0.3$ TU) and the effectiveness of pond-based treatment was variable. The treated wastewater samples at all plants monitored in this study were below $1 \mathrm{TU}$, indicating that only minimal acute toxicity would occur at environmental levels. Discharge of treated wastewater at WWTP 1 and 2 resulted in a 3-5x increase in baseline toxicity in the drain (Fig. 2, top right), but the response was still significantly less than $1 \mathrm{TU}$. The Microtox assay is sensitive to a wide range of compounds, with a strong correlation between "toxicity" and lipophilicity (Tang et al. 2013). The responses with environmental water samples (Fig 2, Microtox, Rivers) therefore indicates the presence of a variety of compounds, but at concentrations that are not acutely toxic to bacteria $(T U<1)$.

RO treatment at AWRP reduced cytotoxicity of the water stream by a further $68 \%$ at least. Low level responses $(<0.05 \mathrm{TU})$ were detectable in 2 out of $4 \mathrm{RO}$ permeate samples and the water at the reference site (Fig 2, Microtox, "RO" and "Ref"). Low level response in highly concentrated water samples (REF > 10) with non-specific assays such as the Microtox has been reported previously (Escher et al. 2008a) and is thought to be an artefact of solvent carry-over during the SPE concentration step. It is of no environmental concern as long as a) it is not considerably above the detection limit (i.e., less than $0.1 \mathrm{TU}$ ) and b) no other specific and/or reactive toxicity are associated with the sample - as was the case here. treated wastewater using the Microtox assay (Macova et al. 2011, Muller et al. 2007). 
Raw sewage contained detectable levels of genotoxicity (Fig. 2, umuC -S9). Aerobic and anaerobic digestion at AWRP resulted in a $15-44 \%$ reduction in genotoxicity. Oxidation at WWTP3 resulted in a 4.9-6.2x increase in genotoxicity to levels above 1 GTU. An increase in genotoxicity in such an environment favouring the creation of reactive compounds is not unexpected, but it should be noted that it was short lived and that genotoxicity dropped below the bioassay threshold after clarification. The genotoxicity of the final wastewater was $60-75 \%$ lower than that of the raw influent, and was similar to that of the secondary wastewater at the AWRP. Genotoxicity was not commonly detected in rural wastewater (WWTP 1 and 2) and was not detected in any of the river water samples. the activity (to $<0.02 \mathrm{TU}$ ). Genotoxicity was not detected in any of the RO permeate samples (Fig. 2).

With the exception of samples from the oxidation ditch, all samples were below 1 GTU. Their discharge into the environment would therefore not be expected to produce significant genotoxicity. The samples from the oxidation ditch, however, were above $1 \mathrm{GTU}$, suggesting that if this water were discharged without further treatment (which is not the case) it may cause adverse effect in exposed microorganisms.

These results are comparable to previous Australian studies, which reported the equivalent of 0.4 GTU in raw sewage and less than $0.02 \mathrm{GTU}$ in treated wastewater using the umuC -S9 assay (Macova et al. 2011, Muller et al. 2007). phytotoxicity above the bioassay threshold of $0.2 \mu \mathrm{g} / \mathrm{L}$ DEQ in most samples (Fig. 2, Max-I-PAM). 
$90 \%$ and $50-86 \%$, respectively. Reverse osmosis removed a further $48 \%$ at least, and all RO permeate samples were below quantification limit ( $<0.03 \mu \mathrm{g} / \mathrm{L}$ DEQ).

The phytotoxicity in rural raw sewage (WWTP 1 and 2) was similar, ranging from 0.04-0.23 $\mu \mathrm{g} / \mathrm{L}$ DEQ.

The overall removal efficacy with the pond-based systems was $47-59 \%$, on average. The phytotoxicity in the treated wastewater was similar to that of the municipal WWTPs, ranging from $<0.03-0.08 \mu \mathrm{g} / \mathrm{L}$ DEQ. Low-level photosynthesis inhibition was detected downstream of WWTP2 discharge $(0.06 \mu \mathrm{g} / \mathrm{L}$ DEQ), but not at WWTP1. All treated wastewater samples were below the bioassay threshold of $0.2 \mu \mathrm{g} / \mathrm{L}$ DEQ (Fig. 2).

These results are comparable to previous Australian studies, which reported up to $0.22 \mu \mathrm{g} / \mathrm{L}$ DEQ in raw sewage, $0.05-0.28 \mu \mathrm{g} / \mathrm{L}$ DEQ in treated wastewater, and up to $0.04 \mu \mathrm{g} / \mathrm{L}$ DEQ in river water (Escher et al. 2006, Macova et al. 2011, Muller et al. 2007). Similar concentrations have been reported in Switzerland, with an average of $0.28 \mu \mathrm{g} / \mathrm{L}$ DEQ in raw sewage, $0.19 \mu \mathrm{g} / \mathrm{L} \mathrm{DEQ}$ in treated wastewater, and up to $0.23 \mu \mathrm{g} / \mathrm{L}$ DEQ in river water (Escher et al. 2008b).

\subsubsection{E-SCREEN assay for estrogenic EDCS}

Raw sewage at the municipal plants (AWRP and WWTP3) was highly estrogenic (Fig. 2, E-SCREEN). Aerobic and anaerobic digestion (at AWRP) reduced estrogenicity by $82-98 \%$, consistent with expectations that estrogens would mineralise and/or absorb to sludge (Andersen et al. 2003). The estrogenicity in the secondary treated wastewater from the municipal treatment plants (AWRP and WWTP3) was still several orders of magnitude higher than a bioassay based threshold of $0.1 \mathrm{ng} / \mathrm{L}$ $E E Q$, suggesting that release of these wastewaters without dilution could cause estrogenic effects in the receiving environment.

Reverse osmosis removed at least $39 \%$ of the remaining estrogenicity, and all RO permeate samples were below detection limit (<0.02 ng/L EEQ). 
321 Estrogenicity at the rural WWTPs (WWTP 1 and 2) was very low, with less than $4.8 \mathrm{ng} / \mathrm{L}$ EEQ in raw sewage and $<0.02 \mathrm{ng} / \mathrm{L}$ EEQ at all other stages. Only river samples upstream and downstream of WWTP2 had detectable estrogenicity, with a $2.2 \times$ increase at the downstream site (up to the bioassay threshold of $0.1 \mathrm{ng} / \mathrm{L}$; Fig. 2, E-SCREEN, "DN2"). This level of estrogenicity suggests that low level estrogenic endocrine effects may be detected in fish collected from that site (see Sections 3.3 and 3.4.2), as well as the existence of upstream sources of estrogenic compounds. EEQ in raw sewage, up to $1.6 \mathrm{ng} / \mathrm{L}$ EEQ in secondary treated wastewater, up to $0.47 \mathrm{ng} / \mathrm{L}$ EEQ in river water, and less than $0.06 \mathrm{ng} / \mathrm{L} \mathrm{EEQ} \mathrm{in} \mathrm{reclaimed} \mathrm{water} \mathrm{in} \mathrm{the} \mathrm{E-SCREEN} \mathrm{assay} \mathrm{(Leusch} \mathrm{et} \mathrm{al.} \mathrm{2010,}$ Macova et al. 2011, Tan et al. 2007).

\subsubsection{AR-CALUX assay for androgenic EDCs}

Raw sewage contained high levels of androgenic compounds, but wastewater treatment was effective at reducing the androgenicity in all treated wastewater samples to below detection limit ( $<2.5 \mathrm{ng} / \mathrm{L} \mathrm{DHTEQ)}$. None of the environmental samples had any detectable level of androgenicity, suggesting that androgenic endocrine disruption is unlikely in organisms in the receiving environment. All RO permeate samples were also below detection limit.

No data could be found on androgenicity in Australian waters, but our results are comparable with a European study, which reported up to $86 \mathrm{ng} / \mathrm{L}$ DHTEQ in raw sewage and 0.75-0.83 ng/L DHTEQ in treated wastewater (van der Linden et al. 2008). 
343 (Table 1). Overall, the chemical data indicates good removal by secondary treatment and, with a few exceptions, hormones were not detected in treated wastewater. Several androgens were routinely detected (particularly the naturally occurring androstenedione, androsterone, etiocholanolone and testosterone). Estrone was the only estrogen commonly detected, including in secondary treated wastewater (Table 1). Three hormones (dihydrotestosterone, 17 $\alpha$-estradiol and $17 \alpha-$ ethynylestradiol) were not detected in any of the samples (reporting limits of 50,5 and $5 \mathrm{ng} / \mathrm{L}$, respectively). None of the monitored chemicals were detected in RO permeate.

The concentrations and observed removal during treatment at the four WWTPs investigated in this study are consistent with previous reports in Australian wastewater (Allinson et al. 2010). The only unusual finding was the observation of the androgenic steroid $17 \beta$-trenbolone in raw influents and primary treated wastewater (although it was not observed in secondary or more highly treated wastewater). $17 \beta$-Trenbolone is the metabolite of the hormone growth promoter $17 \beta$-trenbolone acetate used in beef cattle, suggesting that agricultural run-off may be the source of this chemical. The trenbolone concentrations detected here were in the same range as those previously reported in runoff from beef feedlot in the USA (Durhan et al. 2006).

\subsubsection{Herbicides}

Of all the pesticides monitored (section 2.2.2), only diuron and metolachlor were detected above the reporting limit $(0.025 \mu \mathrm{g} / \mathrm{L})$. treatment was not particularly effective, and concentrations of diuron in treated wastewaters were 
below quantification limit. Metolachlor was detected at the AWRP only, at up to $0.12 \mu \mathrm{g} / \mathrm{L}$ in raw sewage. Primary and secondary treatment removed more than $78 \%$ of the compound.

\subsection{Mosquitofish}

368

There were significant differences between sex ratios at both WWTPs in the September (Spring) and March (Summer) sampling periods but not during the July (Winter) sampling period (Table 2). However, the trends were not consistent between sampling periods and appear to reflect population differences rather than any WWTP impact.

\section{[INSERT TABLE 2 ABOUT HERE]}

There was no consistent effect on GL or PAL at either WWTP 1 or 2 . There were no significant differences between either the GL (ANCOVA, $\left.p_{\text {Sep }}=0.214, p_{\text {Jul }}=0.472\right)$ or PAL (ANCOVA, $p_{\text {Sep }}=0.546$, $\left.\mathrm{p}_{\mathrm{Jul}}=0.091\right)$ of fish captured upstream and downstream of WWTP1 in September 2008 or July 2009. Fish from upstream and downstream of WWTP1 in March 2009 had similar GLs (ANCOVA, $p=0.083$ ). In March 2009 male fish had significantly shorter PALs downstream of WWTP1 compared to fish at the upstream site (ANCOVA, $p=0.038$ ). While this potentially represents an androgenic effect, it was not repeated in any of the other endpoints at any other of the sampling periods. There was also no significant difference between the upstream and downstream sites at WWTP2 in terms of GL $\left(\right.$ ANCOVA, $\left.p_{\text {Sep }}=0.112, p_{\text {Mar }}=0.323, p_{\text {Jul }}=0.472\right)$ or PAL (ANCOVA, $p_{\text {Sep }}=0.104, p_{\text {Mar }}=0.324, p_{\text {Jul }}=$ 0.091). However, when compared to fish from the reference site, fish from downstream of WWTP2 had longer gonopodia (ANCOVA, $p=0.001$ ) and longer PAL (ANCOVA, $p<0.001$ ).

Vitellogenin (Vtg), a precursor to egg yolk, is naturally produced by mature female fish in the lead up to the reproductive season (Summer). Vtg was not detectable in plasma of female fish in Winter (Fig. 3, right, grey bars) but commonly detected in females in Summer (except at the reference site; Fig. 3, right, black bars). Vtg is not normally produced in male fish except upon exposure to estrogenic 
compounds (Sumpter and Jobling 1995). If males were exposed to estrogenic compounds, it could be expected that Vtg would be produced irrespective of the season. Plasma Vtg was not detected in male mosquitofish at WWTP1 and the reference site (Fig. 3, left); however, it was detected in both Summer and Winter sampling periods upstream and downstream of WWTP2 (at low levels compared to female fish). This indicates that these fish were exposed to estrogenic compounds. Given that fish both upstream and downstream of the WWTP outlet displayed this response, it is not possible to attribute this to the presence of the outlet alone. It is likely that upstream sources of EDCs are acting, with the outlet contributing to the EDC load at the downstream site.

[INSERT FIG 3 ABOUT HERE]

\subsection{Comparison of the different methods}

\subsubsection{Comparison of chemical and in vitro bioassay analysis}

Using the concentrations of chemicals and their known potency in the bioassays, it was possible to calculate predicted activity and compare it with the measured response in vitro. This could be done for estrogenicity based on estrogen hormones, androgenicity based on androgen hormones and photosynthesis inhibition based on diuron (Fig 4).

The natural hormones $17 \beta$-estradiol and estriol accounted for most of the predicted estrogenicity in raw and partially treated wastewater (92-94\%), while estriol and estrone accounted for most of the predicted estrogenicity in secondary treated wastewater (90\%). 
estrogenicity than was measured ( 24 of those at WWTP 1 and 2) and 10 measured much higher estrogenicity than predicted. The chemical detection limit for the potent estrogen $17 \alpha-$ ethinylestradiol was comparatively high $(5 \mathrm{ng} / \mathrm{L})$ and it is likely that this compound occurring just below the chemical detection limit explains most of the occurrences of measured higher than predicted estrogenicity. The presence of anti-estrogens may explain the poor agreement between predicted and measured estrogenicity was found at the rural WWTPs 1 and 2. of the predicted androgenicity in raw and primary treated wastewater, while androstenedione alone was responsible for $67-78 \%$ of the predicted androgenicity in partially treated and secondary treated wastewater.

Much better agreement between predicted and measured response was obtained for androgenicity, with all 62 data points falling within an order of magnitude of isometric agreement (Fig 2). This suggests that the 5 androgens measured here by chemical analysis are responsible for most of the androgenicity in the AR-CALUX assay.

When comparing predicted and measured photosynthesis inhibition, there was generally good agreement between the predicted and measured diuron equivalent (with 67 out of 83 data points within an order of magnitude of isometric agreement, Fig 4). There were no samples where the response was lower than predicted, however the measured response was much higher than predicted for $19 \%$ of samples. This is particularly true for raw sewage samples, and suggests the presence of other phytotoxic compounds not accounted for by chemical analysis. Note that measured and predicted photosynthetic inhibition in all secondary and treated wastewater samples were in good agreement, indicating that diuron was the most significant contributor to phytotoxicity in these samples. This suggests that phytotoxic compounds present in raw sewage were removed by wastewater treatment, but that diuron was more persistent. 
There was a good parallel between the findings of the in situ monitoring and both chemical and in vitro bioassay analysis of the treated wastewaters and rivers. Overall, the chemical and in vitro bioassay analysis showed good removal of endocrine-active substances (both estrogenic and androgenic) by wastewater treatment to produce low to undetectable concentrations of estrogenic and androgenic EDCs (Table 1 and Fig 2). Low estrogenicity was detected in the drain upstream and downstream of WWTP2, with the downstream site slightly higher than the upstream site (Fig 2, ESCREEN). Based on these findings, slight estrogenic effects were expected in fish in the WWTP2 drain but not in the WWTP1 drain or at the reference site. This is indeed what was found (Fig 3).

All three lines of evidence (chemical analysis, in vitro bioassay analysis and in situ whole fish monitoring) suggest that treatment at the rural WWTPs monitored in this study is adequate to remove EDCs present in raw sewage to concentrations where they are no longer of concern. In vitro bioassays and in situ monitoring suggest the occurrence of sources of estrogenic EDCs at WWTP2. In vitro bioassays and chemical analysis indicate that the secondary treated wastewater from AWRP and WWTP3 would dilution prior to environmental discharge, otherwise estrogenic effects may arise. Note however that RO treatment was very effective at removing the residual estrogenicity and that the RO permeate did not elicit any response in the E-SCREEN assay ( $<0.02 \mathrm{ng} / \mathrm{LEEQ})$.

\section{Conclusions}

There was significant cytotoxicity, phytotoxicity and estrogenicity in raw sewage, but most of this activity was greatly reduced during standard wastewater treatment. No biological response was detected to RO water, suggesting that reverse osmosis was a significant barrier to biologically active compounds. Chemical analysis and in situ monitoring provided results consistent with the in vitro 
situ sampling did not reveal any evidence of endocrine disruption specifically due to discharge of treated wastewater (although other sources may be present).

This study has demonstrated the utility of combining multiple lines of evidence, including chemical analysis, an in vitro ecotoxicity toolbox, and in situ monitoring in the assessment of water quality. Biomarkers of exposure (in vitro) and effect (in vivo or in situ) are complementary and together provide information with a high level of ecological relevance. It is important however that the assays are used with careful consideration of confounding factors and with a high degree of knowledge of study species and environmental conditions.

\section{Acknowledgment}

Funding for this project was provided through the Raising National Water Standards Program of the advice and assistance with sampling: Guy Watson, Rod Brooks, Jenni Boyle, Wayne Smith and Bill

Department of Water. Richard Lim provided advice on project design and data interpretation. committee.

\section{References}

Allinson, M., Shiraishi, F., Salzman, S.A. and Allinson, G. (2010) In Vitro and Immunological Assessment of the Estrogenic Activity and Concentrations of $17 \beta$-Estradiol, Estrone, and Ethinyl Estradiol in Treated Effluent from 45 Wastewater Treatment Plants in Victoria, Australia. Archives of Environmental Contamination and Toxicology 58(3), 576-586. 
ANZECC/ARMCANZ (2000) Australian guidelines for water quality monitoring and reporting, Agriculture and Resource Management Council of Australia and New Zealand, Agriculture and Resource Management Council of Australia and New Zealand, Canberra, ACT, Australia.

CSIRO \& BOM (2007) Climate change in Australia: Technical report 2007, Commonwealth Science and Industrial Research Organisation (CSIRO) \& Bureau of Meteorology (BOM), Victoria, Australia.

Durhan, E.J., Lambright, C.S., Makynen, E.A., Lazorchak, J., Hartig, P.C., Wilson, V.S., Gray, L.E. and Ankley, G.T. (2006) Identification of metabolites of trenbolone acetate in androgenic runoff from a beef feedlot. Environmental Health Perspectives 114(S1), 65-68.

Escher, B. and Leusch, F. (2012) Bioanaytical tools in water quality assessment. With contributions by Chapman $\mathrm{H}$ and Poulsen A, IWA Publishing, London, UK.

Escher, B.I., Bramaz, N., Mueller, J.F., Quayle, P., Rutishauser, S. and Vermeirssen, E.L.M. (2008a) Toxic equivalent concentrations (TEQs) for baseline toxicity and specific modes of action as a tool to improve interpretation of ecotoxicity testing of environmental samples. Journal of Environmental Monitoring 10(5), 612-621.

Escher, B.I., Bramaz, N., Quayle, P., Rutishauser, S. and Vermeirssen, E.L.M. (2008b) Monitoring of the ecotoxicological hazard potential by polar organic micropollutants in sewage treatment plants and surface waters using a mode-of-action based test battery. Journal of Environmental Monitoring 10(5), 622-631.

Escher, B.I., Quayle, P., Muller, R., Schreiber, U. and Mueller, J.F. (2006) Passive sampling of herbicides combined with effect analysis in algae using a novel high-throughput phytotoxicity assay (Maxi-Imaging-PAM). Journal of Environmental Monitoring 8(4), 456-464.

Game, C., Gagnon, M.M., Webb, D. and Lim, R. (2006) Endocrine disruption in male mosquitofish (Gambusia holbrooki) inhabiting wetlands in Western Australia. Ecotoxicology 15(8), 665-672. ISO (2000) Water quality -- Determination of the genotoxicity of water and waste water using the umu-test (ISO 13829:2000), International Organization for Standardization, Geneva, Switzerland. 
505

506

507

508

509

510

511

512

513

514

515

516

517

518

519

520

521

522

523

524

525

526

527

528

529

ISO (2007) Water quality -- Determination of the inhibitory effect of water samples on the light emission of Vibrio fischeri (Luminescent bacteria test) -- Part 3: Method using freeze-dried bacteria (ISO 11348-3:2007), International Organization for Standardization, Geneva, Switzerland.

Le-Minh, N., Coleman, H.M., Khan, S.J., van Luer, Y., Trang, T.T.T., Watkins, G. and Stuetz, R.M.

(2010) The application of membrane bioreactors as decentralised systems for removal of endocrine disrupting chemicals and pharmaceuticals. Water Science and Technology 61(5), 10811088.

Leusch, F.D.L., Chapman, H.F., Körner, W., Gooneratne, S.R. and Tremblay, L.A. (2005) Efficacy of an advanced sewage treatment plant in southeast Queensland, Australia, to remove estrogenic chemicals. Environmental Science and Technology 39(15), 5781-5786.

Leusch, F.D.L., de Jager, C., Levi, Y., Lim, R., Puijker, L., Sacher, F., Tremblay, L.A., Wilson, V.S. and Chapman, H.F. (2010) Comparison of Five in Vitro Bioassays to Measure Estrogenic Activity in Environmental Waters. Environmental Science \& Technology 44(10), 3853-3860.

Leusch, F.D.L., van den Heuvel, M.R., Chapman, H.F., Gooneratne, S.R., Eriksson, A.M.E. and Tremblay, L.A. (2006) Development of methods for extraction and in vitro quantification of estrogenic and androgenic activity of wastewater samples. Comparative Biochemistry and Physiology Part C 143(1), 117-126.

Macova, M., Toze, S., Hodgers, L., Mueller, J.F., Bartkow, M.E. and Escher, B.I. (2011) Bioanalytical tools for the evaluation of organic micropollutants during sewage treatment, water recycling and drinking water generation. Water Research 45, 4238-4247.

Muller, R., Tang, J.Y., Thier, R. and Mueller, J.F. (2007) Combining passive sampling and toxicity testing for evaluation of mixtures of polar organic chemicals in sewage treatment plant effluent. Journal of Environmental Monitoring 9(1), 104-109.

NRMMC/EPHC/NHMRC (2008) Australian Guidelines for Water Recycling: Managing health and environmental risks (Phase 2) - Augmentation of drinking water supplies., p. 174pp., Natural 

National Health and Medical Research Council.

Power, E.A. and Boumphrey, R.S. (2004) International Trends in Bioassay Use for Effluent Management. Ecotoxicology 13(5), 377-398.

Rawson, C.A., Tremblay, L.A., Warne, M.S.J., Ying, G.-g., Kookana, R., Laginestra, E., Chapman, J.C. and Lim, R.P. (2009) Bioactivity of POPs and their effects in mosquitofish in Sydney Olympic Park, Australia. Science of the Total Environment 407(12), 3721-3730.

Schreiber, U., Quayle, P., Schmidt, S., Escher, B.I. and Mueller, J.F. (2007) Methodology and evaluation of a highly sensitive algae toxicity test based on multiwell chlorophyll fluorescence imaging. Biosensors \& Bioelectronics 22(11), 2554-2563.

Sonneveld, E., Jansen, H.J., Riteco, J.A.C., Brouwer, A. and van der Burg, B. (2005) Development of androgen- and estrogen-responsive bioassays, members of a panel of human cell line-based highly selective steroid-responsive bioassays. Toxicological Sciences 83(1), 136-148. The E-Screen assay as a tool to identify estrogens: an update on estrogenic environmental pollutants. Environmental Health Perspectives 103(S7), 113-122.

Sumpter, J.P. and Jobling, S. (1995) Vitellogenesis as a biomarker for estrogenic contamination of the aquatic environment. Environmental Health Perspectives 103(S7), 173-178. Comprehensive study of endocrine disrupting compounds using grab and passive sampling at selected wastewater treatment plants in South East Queensland, Australia. Environment International 33(5), 654-669.

Tang, J.Y.M., McCarty, S., Glenn, E., Neale, P.A., Warne, M.S.J. and Escher, B.I. (2013) Mixture effects of organic micropollutants present in water: Towards the development of effect-based water quality trigger values for baseline toxicity. Water Research 47(10), 3300-3314. 
556 Burg, B. (2008) Detection of multiple hormonal activities in wastewater effluents and surface

557 water, using a panel of steroid receptor CALUX bioassays. Environmental Science \& Technology

$558 \quad 42(15), 5814-5820$.

559 Water Corporation (2013) Groundwater Replenishment Trial - Final Report, Water Corporation,

560 Perth, Western Australia, Australia.

561

562 


\begin{tabular}{|c|c|c|c|c|c|c|c|c|c|c|c|c|c|c|}
\hline & & AWRP & & & & WWTP1 & & & WWTP2 & & & WWTP3 & & \\
\hline Chemical & $\begin{array}{c}\text { Sampling } \\
\text { date }\end{array}$ & Inf & 19 & 20 & RO & Inf & IP & Eff & Inf & IP & Eff & Inf & IP & Eff \\
\hline \multirow[t]{4}{*}{ Androstenedione } & Mar-08 & $340 \pm 91$ & $170 \pm 2.8$ & $6.3 \pm 0.6$ & $<1$ & NA & NA & NA & NA & NA & NA & NA & NA & NA \\
\hline & Jun-08 & $490 \pm 90$ & $400 \pm 25$ & $7.2 \pm 0.9$ & $<1$ & $54 \pm 7.8$ & $14 \pm 4.9$ & $17 \pm 0.7$ & $180 \pm 4.9$ & $14 \pm 1.4$ & $10 \pm 0.7$ & $270 \pm 9.9$ & $15 \pm 0.7$ & $7.6 \pm 0.4$ \\
\hline & Sep-08 & $310 \pm 120$ & $290 \pm 7.1$ & $13 \pm 0.7$ & $<1$ & $69 \pm 7.1$ & $4.8 \pm 0.3$ & $3.3 \pm 0.7$ & $14 \pm 2.1$ & $<1$ & $<1$ & $30 \pm 1.4$ & $20 \pm 2.1$ & $5.1 \pm 0.6$ \\
\hline & Mar-09 & NA & NA & NA & NA & $<1$ & $<1$ & $<1$ & $<1$ & $<1$ & $<1$ & $170 \pm 1.4$ & $15 \pm 0.1$ & $3.2 \pm 0.2$ \\
\hline \multirow[t]{4}{*}{ Androsterone } & Mar-08 & NA & NA & $<50$ & $<50$ & NA & NA & NA & NA & NA & NA & NA & NA & NA \\
\hline & Jun-08 & NA & NA & $<50$ & $<50$ & $430 \pm 110$ & $<50$ & $<50$ & $800 \pm 74$ & $70 \pm 21$ & $67 \pm 3.5$ & $5400 \pm 1300$ & $86^{(\text {a) }}$ & $<50$ \\
\hline & Sep-08 & $1600 \pm 690$ & $1500 \pm 49$ & $<50$ & $<50$ & $610 \pm 17$ & $<50$ & $<50$ & $78 \pm 2.8$ & $<50$ & $<50$ & $460 \pm 7.7$ & $<50$ & $<50$ \\
\hline & Mar-09 & NA & NA & NA & NA & $<50$ & $<50$ & $<50$ & $280 \pm 1.4$ & $<50$ & $<50$ & $1600 \pm 14$ & $<50$ & $<50$ \\
\hline \multirow{4}{*}{ Etiocholanolone } & Mar-08 & NA & NA & $<100$ & $<100$ & NA & NA & NA & NA & NA & NA & NA & NA & NA \\
\hline & Jun-08 & NA & NA & $<100$ & $<100$ & $420 \pm 32$ & $<100$ & $<100$ & $980 \pm 14$ & $180 \pm 20$ & $180 \pm 52$ & $4900 \pm 1500$ & $<100$ & $<100$ \\
\hline & Sep-08 & $3000 \pm 270$ & $1600 \pm 70$ & $180 \pm 25$ & $<100$ & $940 \pm 28$ & $<100$ & $<100$ & $150 \pm 4.9$ & $<100$ & $<100$ & $1100 \pm 17$ & $470 \pm 26$ & $180 \pm 96$ \\
\hline & Mar-09 & NA & NA & NA & NA & $290 \pm 0.7$ & $<100$ & $<100$ & $1000 \pm 2.1$ & $<100$ & $<100$ & $2600 \pm 7.1$ & $<100$ & $<100$ \\
\hline \multirow[t]{4}{*}{ Testosterone } & Mar-08 & $76 \pm 2.8$ & $49 \pm 1.4$ & $<1$ & $<1$ & NA & NA & NA & NA & NA & NA & NA & NA & NA \\
\hline & Jun-08 & $110 \pm 1.4$ & $130 \pm 0.3$ & $<1$ & $<1$ & $5.4 \pm 0.5$ & $<1$ & $<1$ & $9.2 \pm 0.1$ & $<1$ & $<1$ & $91 \pm 1.4$ & $<1$ & $<1$ \\
\hline & Sep-08 & $91 \pm 24$ & $100 \pm 0.7$ & $<1$ & $<1$ & $7.8 \pm 0.6$ & $<1$ & $<1$ & $<1$ & $<1$ & $<1$ & $13 \pm 0.7$ & $4.9 \pm 0.8$ & $1.2 \pm 0.1$ \\
\hline & Mar-09 & NA & NA & NA & NA & $<1$ & $<1$ & $<1$ & $<1$ & $<1$ & $<1$ & $59 \pm 0.5$ & $2.5 \pm 0.4$ & $2.4 \pm 0.1$ \\
\hline \multirow[t]{4}{*}{ Dihydrotestosterone } & Mar-08 & $<50$ & $<50$ & $<50$ & $<50$ & NA & NA & NA & NA & NA & NA & NA & NA & NA \\
\hline & Jun-08 & $<50$ & $<50$ & $<50$ & $<50$ & $<50$ & $<50$ & $<50$ & $<50$ & $<50$ & $<50$ & $<50$ & $<50$ & $<50$ \\
\hline & Sep-08 & $<50$ & $<50$ & $<50$ & $<50$ & $<50$ & $<50$ & $<50$ & $<50$ & $<50$ & $<50$ & $<50$ & $<50$ & $<50$ \\
\hline & Mar-09 & NA & NA & NA & NA & $<50$ & $<50$ & $<50$ & $<50$ & $<50$ & $<50$ & $<50$ & $<50$ & $<50$ \\
\hline \multirow{4}{*}{$\begin{array}{l}\text { Testosterone } \\
\text { propionate }\end{array}$} & Mar-08 & $<5$ & $<5$ & $<5$ & $<5$ & NA & NA & NA & NA & NA & NA & NA & NA & NA \\
\hline & Jun-08 & $<5$ & $<5$ & $<5$ & $<5$ & $<5$ & $<5$ & $<5$ & $<5$ & $<5$ & $<5$ & $<5$ & $<5$ & $<5$ \\
\hline & Sep-08 & $17 \pm 3.5$ & $22 \pm 2.1$ & $<5$ & $<5$ & $9.2 \pm 0.8$ & $<5$ & $<5$ & $<5$ & $<5$ & $<5$ & $14 \pm 2.8$ & $<5$ & $<5$ \\
\hline & Mar-09 & NA & NA & NA & NA & $<5$ & $<5$ & $<5$ & $<5$ & $<5$ & $<5$ & $<5$ & $<5$ & $<5$ \\
\hline $17 \beta$-Trenbolone & Mar-08 & $<5$ & $<5$ & $<5$ & $<5$ & NA & NA & NA & NA & NA & NA & NA & NA & NA \\
\hline
\end{tabular}




\begin{tabular}{|c|c|c|c|c|c|c|c|c|c|c|c|c|c|c|}
\hline & Jun-08 & $<5$ & $<5$ & $<5$ & $<5$ & $<5$ & $<5$ & $<5$ & $24 \pm 2.1$ & $<5$ & $<5$ & $64 \pm 12$ & $<5$ & $<5$ \\
\hline & Sep-08 & $120 \pm 27$ & $110 \pm 5.7$ & $<5$ & $<5$ & $<5$ & $<5$ & $<5$ & $13 \pm 0.7$ & $<5$ & $<5$ & $48 \pm 5.6$ & $<5$ & $<5$ \\
\hline & Mar-09 & NA & NA & NA & NA & $<5$ & $<5$ & $<5$ & $<5$ & $<5$ & $<5$ & $<5$ & $<5$ & $<5$ \\
\hline \multirow[t]{4}{*}{$17 \beta$-Estradiol } & Mar-08 & $<5$ & $<5$ & $<5$ & $<5$ & NA & NA & NA & NA & NA & NA & NA & NA & NA \\
\hline & Jun-08 & $<5$ & $<5$ & $<5$ & $<5$ & $<5$ & $<5$ & $<5$ & $<5$ & $<5$ & $<5$ & $29 \pm 1.4$ & $8^{(a)}$ & $<5$ \\
\hline & Sep-08 & $24 \pm 7.8$ & $19 \pm 1.4$ & $<5$ & $<5$ & $<5$ & $<5$ & $<5$ & $<5$ & $<5$ & $<5$ & $80 \pm 4.9$ & $23 \pm 2.8$ & $<5$ \\
\hline & Mar-09 & NA & NA & NA & NA & $<5$ & $<5$ & $<5$ & $<5$ & $<5$ & $<5$ & $<5$ & $<5$ & $<5$ \\
\hline \multirow[t]{4}{*}{ 17a-Estradiol } & Mar-08 & $<5$ & $<5$ & $<5$ & $<5$ & NA & NA & NA & NA & NA & NA & NA & NA & NA \\
\hline & Jun-08 & $<5$ & $<5$ & $<5$ & $<5$ & $<5$ & $<5$ & $<5$ & $<5$ & $<5$ & $<5$ & $<5$ & $<5$ & $<5$ \\
\hline & Sep-08 & $<5$ & $<5$ & $<5$ & $<5$ & $<5$ & $<5$ & $<5$ & $<5$ & $<5$ & $<5$ & $<5$ & $<5$ & $<5$ \\
\hline & Mar-09 & NA & NA & NA & NA & $<5$ & $<5$ & $<5$ & $<5$ & $<5$ & $<5$ & $<5$ & $<5$ & $<5$ \\
\hline \multirow[t]{4}{*}{ Estrone } & Mar-08 & NA & $220 \pm 9.2$ & $25 \pm 5.6$ & $<5$ & NA & NA & NA & NA & NA & NA & NA & NA & NA \\
\hline & Jun-08 & NA & NA & $34 \pm 4.2$ & $<5$ & $32 \pm 4.9$ & $30 \pm 14$ & $37 \pm 9.2$ & $430 \pm 160$ & $160 \pm 26$ & $77 \pm 34$ & NA & $95^{(a)}$ & $100 \pm 110$ \\
\hline & Sep-08 & $390 \pm 180$ & $280 \pm 59$ & $67 \pm 2.8$ & $<5$ & $74 \pm 6.4$ & $18 \pm 2.1$ & $13 \pm 7.1$ & $31 \pm 3.5$ & $20 \pm 0.7$ & $<5$ & NA & $60 \pm 2.1$ & $<5$ \\
\hline & Mar-09 & NA & NA & NA & NA & $35 \pm 2.1$ & $<5$ & $<5$ & $57 \pm 1.9$ & $<5$ & $<5$ & $310 \pm 5.7$ & $18 \pm 0.9$ & $16 \pm 0.6$ \\
\hline \multirow[t]{4}{*}{ Estriol } & Mar-08 & $<50$ & $<50$ & $<50$ & $<50$ & NA & NA & NA & NA & NA & NA & NA & NA & NA \\
\hline & Jun-08 & $<50$ & $<50$ & $<50$ & $<50$ & $<50$ & $<50$ & $<50$ & $<50$ & $<50$ & $<50$ & $<50$ & $<50$ & $<50$ \\
\hline & Sep-08 & $820 \pm 460$ & $800 \pm 7.1$ & $69 \pm 5$ & $<50$ & $260 \pm 18$ & $190 \pm 17$ & $170 \pm 20$ & $93 \pm 24$ & $140 \pm 7.1$ & $58 \pm 11$ & $620 \pm 17$ & $89 \pm 9.2$ & $<50$ \\
\hline & Mar-09 & NA & NA & NA & NA & $<50$ & $<50$ & $<50$ & $<50$ & $<50$ & $<50$ & $<50$ & $<50$ & $<50$ \\
\hline \multirow[t]{4}{*}{$17 \alpha$-Ethinylestradiol } & Mar-08 & $<5$ & $<5$ & $<5$ & $<5$ & NA & NA & NA & NA & NA & NA & NA & NA & NA \\
\hline & Jun-08 & $<5$ & $<5$ & $<5$ & $<5$ & $<5$ & $<5$ & $<5$ & $<5$ & $<5$ & $<5$ & $<5$ & $<5$ & $<5$ \\
\hline & Sep-08 & $<5$ & $<5$ & $<5$ & $<5$ & $<5$ & $<5$ & $<5$ & $<5$ & $<5$ & $<5$ & $<5$ & $<5$ & $<5$ \\
\hline & Mar-09 & NA & NA & NA & NA & $<5$ & $<5$ & $<5$ & $<5$ & $<5$ & $<5$ & $<5$ & $<5$ & $<5$ \\
\hline \multirow[t]{5}{*}{ Diuron } & Mar-08 & NA & $\mathrm{NA}$ & NA & NA & NA & NA & NA & NA & NA & NA & NA & NA & NA \\
\hline & Jun-08 & NA & NA & NA & NA & $<25$ & $26 \pm 0.1$ & $<25$ & $<25$ & $<25$ & $<25$ & $<25$ & $26 \pm 18$ & $29 \pm 4.1$ \\
\hline & Sep-08 & $38 \pm 6.1$ & $44 \pm 7.6$ & $50 \pm 2.1$ & $<25$ & $<25$ & $<25$ & $<25$ & $<25$ & $<25$ & $<25$ & $<25$ & $32 \pm 27$ & $55 \pm 8.9$ \\
\hline & Dec-08 & $100 \pm 18$ & $150 \pm 16$ & $130 \pm 5.3$ & $<25$ & $<25$ & NA & $<25$ & $<25$ & NA & $<25$ & $32 \pm 2.4$ & $78 \pm 11$ & $64 \pm 1.9$ \\
\hline & Mar-09 & NA & NA & NA & NA & $39 \pm 0.1$ & $36 \pm 3.5$ & $<25$ & $30 \pm 8$ & $32 \pm 0.3$ & $<25$ & $<25$ & $25 \pm 17$ & $28 \pm 2.5$ \\
\hline \multirow[t]{5}{*}{ Metolachlor } & Mar-08 & NA & NA & NA & NA & NA & NA & NA & NA & NA & NA & NA & NA & NA \\
\hline & Jun-08 & NA & NA & NA & NA & $<25$ & $<25$ & $<25$ & $<25$ & $<25$ & $<25$ & $<25$ & $<25$ & $<25$ \\
\hline & Sep-08 & $120 \pm 24$ & $76 \pm 0.1$ & $26 \pm 0.5$ & $<25$ & $<25$ & $<25$ & $<25$ & $<25$ & $<25$ & $<25$ & $<25$ & $<25$ & $<25$ \\
\hline & Dec-08 & $32 \pm 2.4$ & $29 \pm 1.1$ & $<25$ & $<25$ & $<25$ & NA & $<25$ & $<25$ & NA & $<25$ & $<25$ & $<25$ & $<25$ \\
\hline & Mar-09 & NA & NA & NA & NA & $<25$ & $<25$ & $<25$ & $<25$ & $<25$ & $<25$ & $<25$ & $<25$ & $<25$ \\
\hline
\end{tabular}


Table 2. Population and morphometric endpoints for mosquitofish captured upstream and

570 downstream of WWTPs 1 and 2 and at a reference site ("Ref"). "GL" = gonopodial length; "PAL" =

571 pre-anal length (distance from the gonopodium to the snout). Values for GL and PAL are average \pm

572 SEM. * Statistically different from corresponding upstream site $(\alpha=0.05)$. + Statistically different from reference site $(\alpha=0.05)$.

\begin{tabular}{|l|l|c|c|c|c|c|}
\hline & & WWTP1 & & WWTP2 & Reference \\
\hline & $\begin{array}{c}\text { Upstream } \\
\text { (UP1) }\end{array}$ & $\begin{array}{c}\text { Downstream } \\
\text { (DN1) }\end{array}$ & $\begin{array}{c}\text { Upstream } \\
\text { (UP2) }\end{array}$ & $\begin{array}{c}\text { Downstream } \\
\text { (DN2) }\end{array}$ & \\
\hline Males (\%) & Sep 2008 & $28(14 \%)$ & $14(16 \%)$ & $84(23 \%)$ & $11(12 \%)$ & $5(6 \%)$ \\
\hline & Mar 2009) & $48(34 \%)$ & $16(16 \%)$ & $40(31 \%)$ & $37(29 \%)$ & $47(34 \%)$ \\
\hline & Jul 2009 & $6(38 \%)$ & $5(22 \%)$ & $50(23 \%)$ & $14(19 \%)$ & $9(21 \%)$ \\
\hline GL (mm) & Sep 2008 & $6.83 \pm 0.11$ & $6.76 \pm 0.08$ & $6.79 \pm 0.06$ & $7.05 \pm 0.09$ & $6.97 \pm 0.24$ \\
\hline & Mar 2009 & $6.90 \pm 0.07$ & $6.91 \pm 0.12$ & $7.04 \pm 0.08$ & $7.46 \pm 0.07 \dagger$ & $7.15 \pm 0.08$ \\
\hline & Jul 2009 & $7.00 \pm 0.23$ & $6.75 \pm 0.28$ & $6.55 \pm 0.68$ & $6.76 \pm 0.15$ & $6.78 \pm 0.15$ \\
\hline PAL (mm) & Sep 2008 & $8.93 \pm 0.17$ & $8.64 \pm 0.09$ & $8.67 \pm 0.09$ & $9.71 \pm 0.22$ & $9.37 \pm 0.33$ \\
\hline & Mar 2009 & $9.48 \pm 0.10 \dagger$ & $9.04 \pm 0.18 *$ & $9.56 \pm 0.10$ & $10.13 \pm 0.11 \dagger$ & $9.54 \pm 0.11$ \\
\hline & Jul 2009 & $9.24 \pm 0.29$ & $8.80 \pm 0.40$ & $9.11 \pm 0.11$ & $9.64 \pm 0.18$ & $9.20 \pm 0.24$ \\
\hline
\end{tabular}


A. AWRP

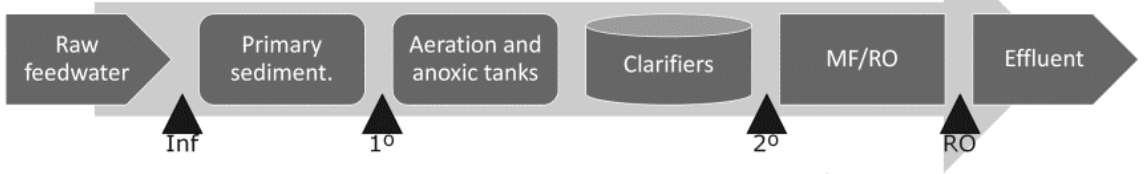

B. WWTP1

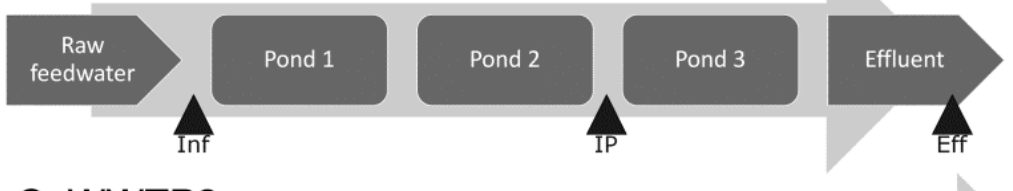

C. WWTP2

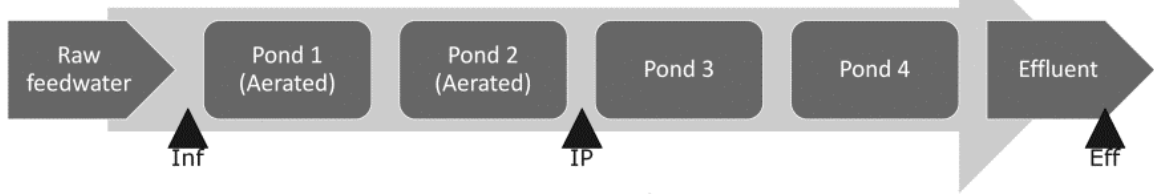

D. WWTP3

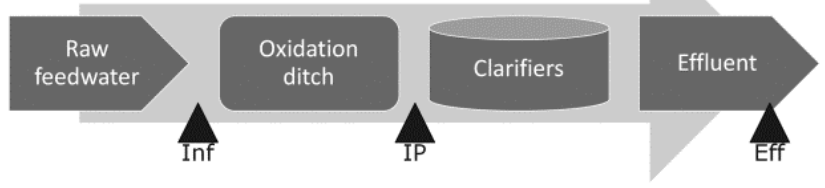

576

577 Figure 1. Treatment train and sampling locations. "AWRP" = Advanced Water Reclamation Plant;

578 "WWTP" = Wastewater Treatment Plant; "Inf" = Influent (raw sewage); "10" = Primary treated

579 wastewater; "2o" = Secondary treated wastewater; "RO" = Reverse osmosis permeate; "IP" = In-plant

580 sample; "Eff" = Effluent (treated wastewater).

581 

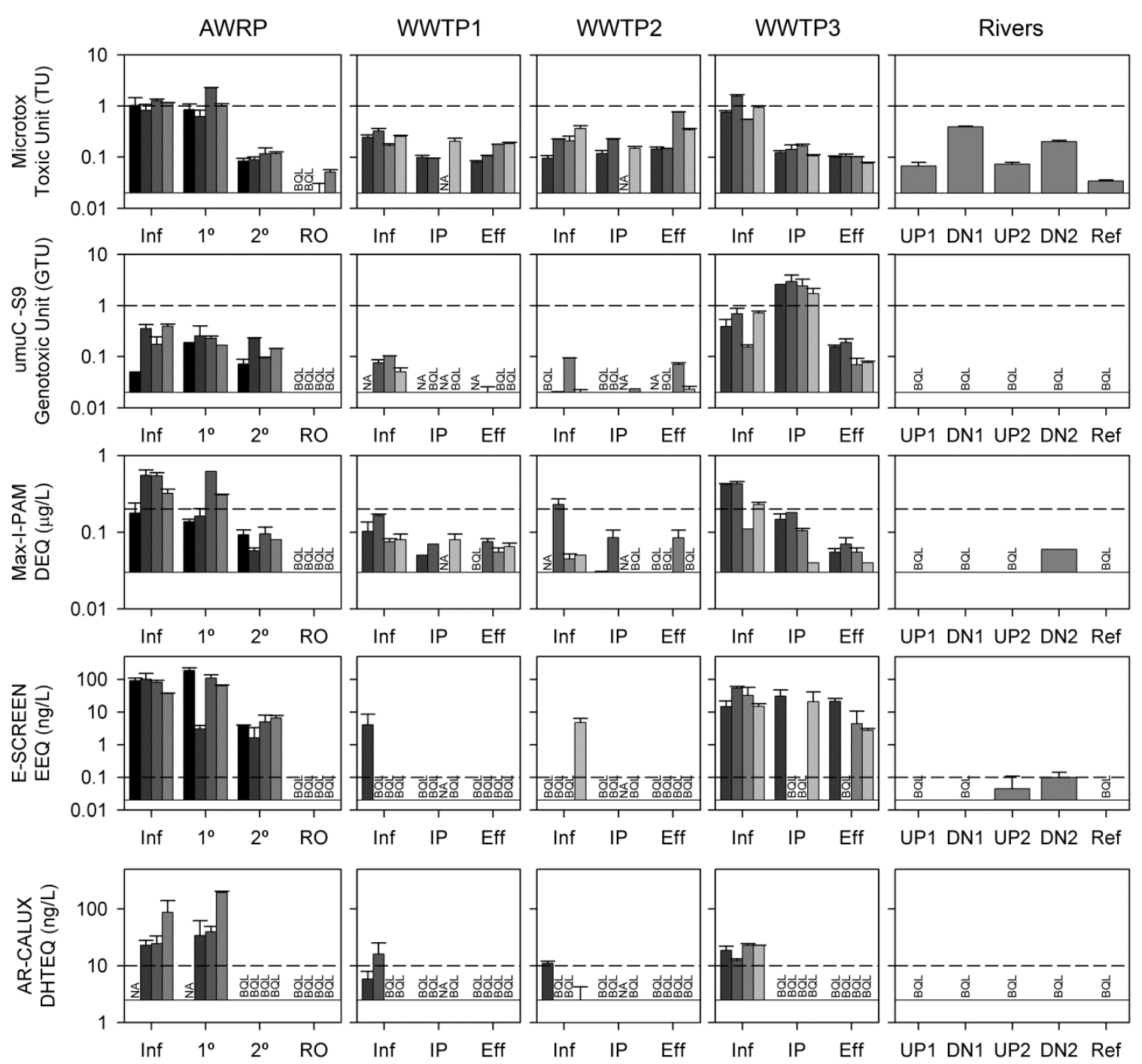

September 2008

December 2008

March 2009

Figure 2. Bioanalytical results. The dotted line represents the bioassay threshold above which the in vitro response is expected to lead to adverse effects in exposed organisms. "AWRP" = Advanced

Water Reclamation Plant; "WWTP" = Wastewater Treatment Plant; "Inf" = Influent (raw sewage);

"10" = Primary treated wastewater; "2"= = Secondary treated wastewater; "RO" = Reverse osmosis

permeate; "IP" = In-plant sample; "Eff" = Effluent (treated wastewater); "UP1" and "DN1" =

Upstream and downstream of WWTP1, respectively; "UP2" and "DN2" = Upstream and downstream of WWTP2, respectively; "Ref" = Reference site; "NA" = Not available; "BQL" = Below quantification limit (quantification limit specified in Table 1). $n=2$ independent samples. 

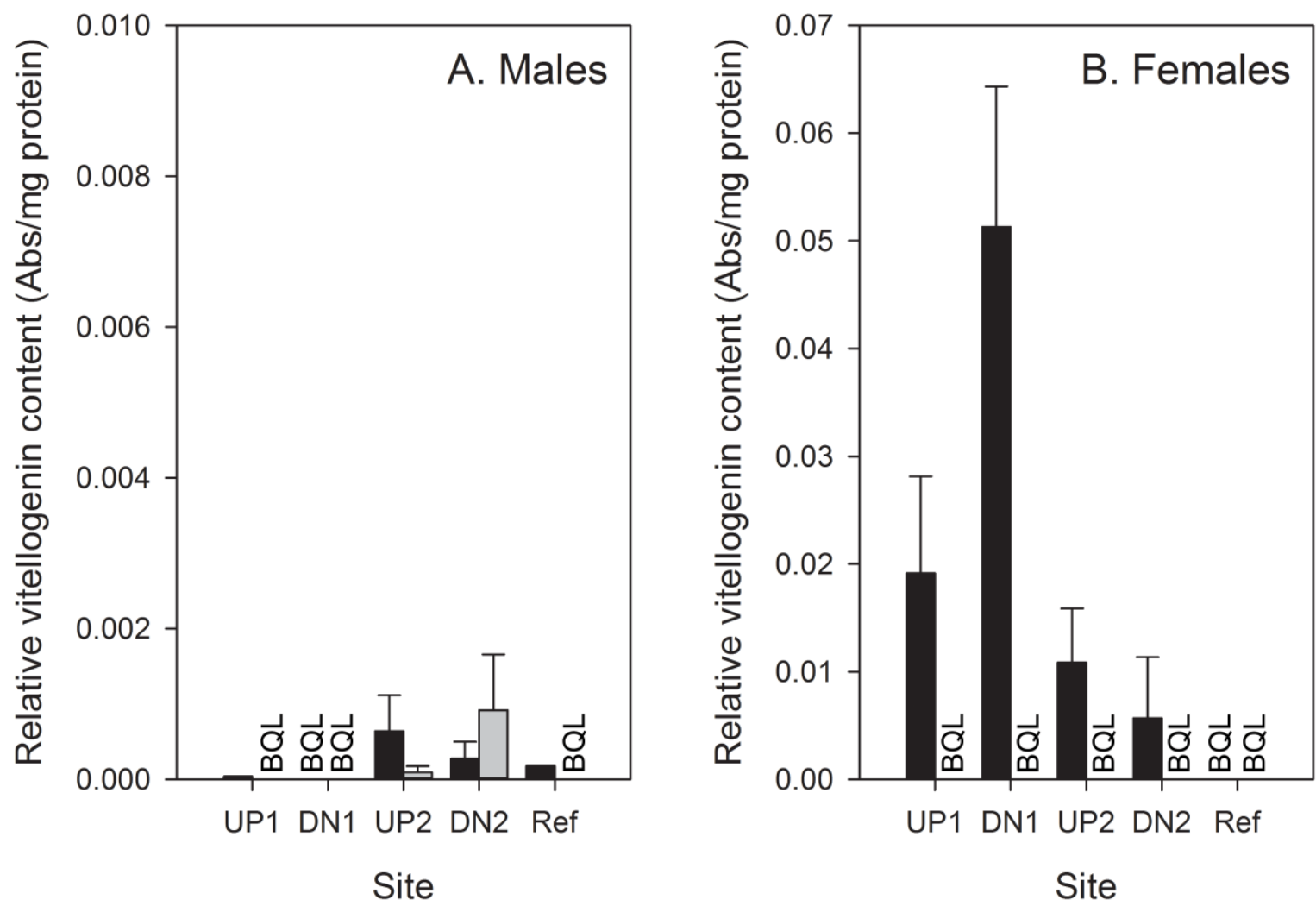

593 Figure 3. Relative vitellogenin content of male (left) and female (right) mosquitofish from upstream

594 and downstream of WWTP1 ("UP1" and "DN1", respectively) and WWTP2 ("UP2" and "DN2",

595 respectively) and at the reference site ("Ref"). Black bars = Summer (Mar 09), grey bars = winter (Jul

596 09). "BQL" = Below Detection Limit. 
AWRP
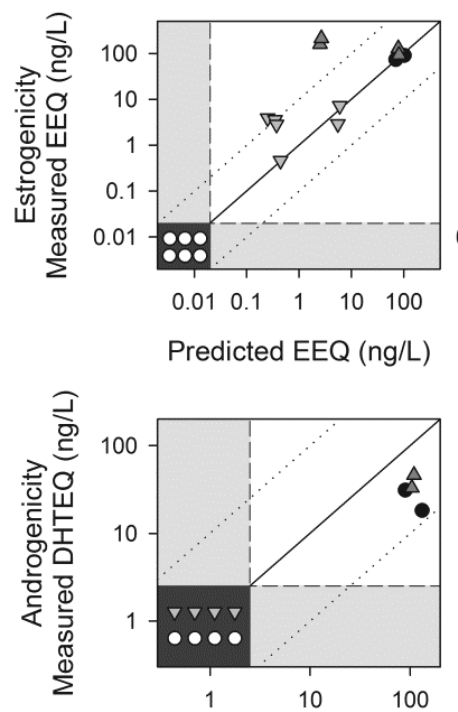

Predicted DHTEQ (ng/L)

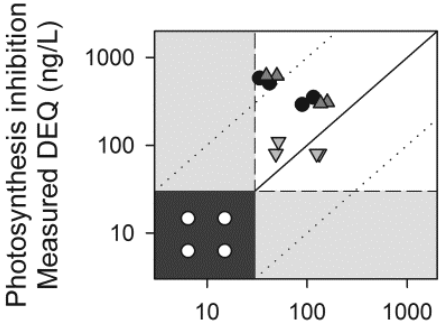

Predicted DEQ (ng/L)

WWTP1
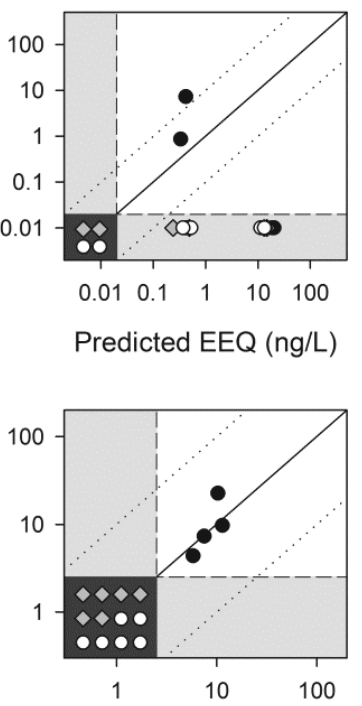

Predicted DHTEQ (ng/L)

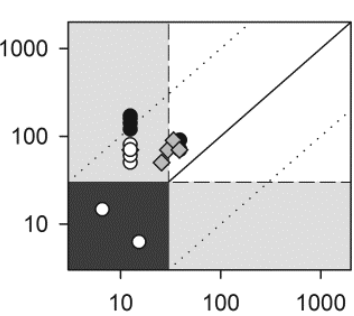

Predicted DEQ (ng/L)
WWTP2

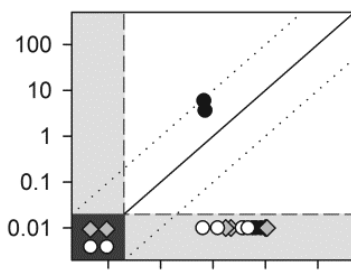

$\begin{array}{lllll}0.01 & 0.1 & 1 & 10 & 100\end{array}$

Predicted EEQ (ng/L)

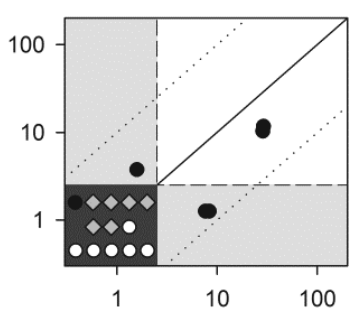

Predicted DHTEQ (ng/L)

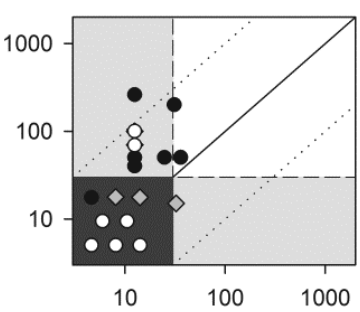

Predicted DEQ (ng/L)
WWTP3

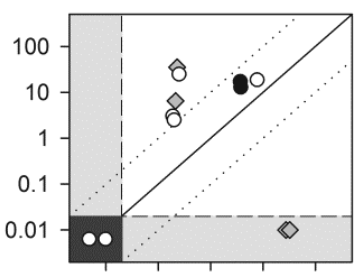

$\begin{array}{lllll}0.01 & 0.1 & 1 & 10 & 100\end{array}$

Predicted EEQ (ng/L)

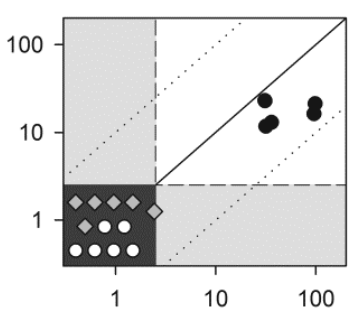

Predicted DHTEQ (ng/L)

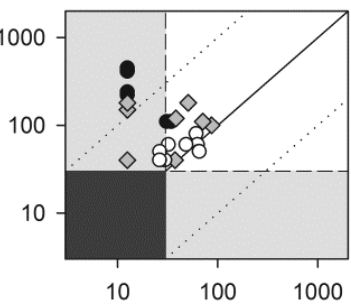

Predicted DEQ (ng/L)

Figure 4. Comparison of predicted vs. measured estrogenicity (as 17ß-estradiol equivalent, EEQ; top), androgenicity (as dihydrotestosterone equivalent, DHTEQ; middle) and photosynthesis inhibition (as diuron equivalent, DEQ; bottom). The predicted in vitro response was calculated from chemical concentrations of selected compounds multiplied by the potency of each compound in the relevant assay. Predicted estrogenicity was calculated from $17 \beta$-estradiol $(R P=1)$, estrone $(R P=0.012)$ and estriol $(\mathrm{RP}=0.071)$ concentrations; predicted androgenicity was calculated from androstenedione $(R P=0.057)$, androsterone $(R P=0.006)$, testosterone $(R P=0.21)$, testosterone propionate $(R P=$ $0.20)$ and $17 \beta$-trenbolone $(\mathrm{RP}=0.50)$; photosynthesis inhibition was calculated from diuron alone $(\mathrm{RP}=1)$. "AWRP" = Advanced Water Reclamation Plant; "WWTP" = Wastewater Treatment Plant. $\bullet=$ Influent (raw sewage; "Inf"); $\Delta$ = Primary treated wastewater ("1ㅇ"); $\nabla=$ Secondary treated wastewater ("2"); $O=$ Effluent ("RO" and "Eff"); $\diamond=$ In-plant sample ("IP"). Dark gray areas at the bottom left of each graph indicates below detection limit of both methods; light gray area at the 
611 bottom and left of each graph indicates areas below the bioanalytical quantification limit and 612 chemical quantification limit, respectively. 